\title{
13 - SCREENING AND RISK FACTORS FOR PERINATAL MOOD DISORDERS IN SOUTHERN BRAZIL
}

\section{F. Schier De Fraga, D. Zorzetto,N. Sobieray, V. Ferreira do Amaral, L. Gaede Senesi, E. Serman, A. \\ Lacerda, G. Schier de Fraga, C. Pecharki, A. Tavares da Silva Sequinel, P.}

Pereira Alvim, G. Oliveira

Garcia

\section{Background}

Pregnancy depression among Brazilians can range 7.2 to $43 \%$. Thus, the recognition of vulnerable patients becomes essencial to early approach

\section{Objectives}

To demonstrate the importance of perinatal mood disorders screening.

\section{Methods}

Women under 28 weeks of gestational age answered the questionnaires "Gestacional Profile", "Edinburgh Postpartum Depression Scale" and "Mood Disorders Questionnaire". A new interview happened between 3440w and 48 hours after delivery in this one was associated the "Puerperium Profile" questionnaire. Patients referred to psychiatry (EPDS $\geq 13$ or/and MDQ positive) received the final diagnosis and follow-up. The study was approved by the Ethical Committee on Human Research of Hospital de Clínicas da UFPR.

\section{Results}

$50 \%$ of the 30 patients interviewed were referred to psychiatry, and "Depressive disorder" was the stand out diagnosis $\quad(33 \%)$. Planned pregnancy (RR 0.56, Cl 0.17 1.75) and breastfeeding ( $p$ 0.095) were protective factors. Family and personal history of mental disorders were shown as risk factors- alcoholism (RR 3.85, Cl 2.03-7.29), bipolar disorder (RR 3.22, $\mathrm{Cl}$ 1.87-5.54) and depression (RR 2.75, Cl 1.077.03). Satisfaction with relationship might be a protective fator ( $R R \quad 0.25 ; \mathrm{Cl}$ 0.13-0.49), while abusive relationship (partner humiliation and aggressiveness) are risk factors (RR 3.5, Cl 1.29-9.47 and RR $3.85, \mathrm{Cl} 2.04-7.29$ respectively).

\section{Conclusion}

To include the screening for mood disorders in prenatal follow-up might be costeffective, contributing to the reduction of the stigma and improving the quality of life of the patient and their families.

\section{Patients refered to psychiatry and diagnosis}

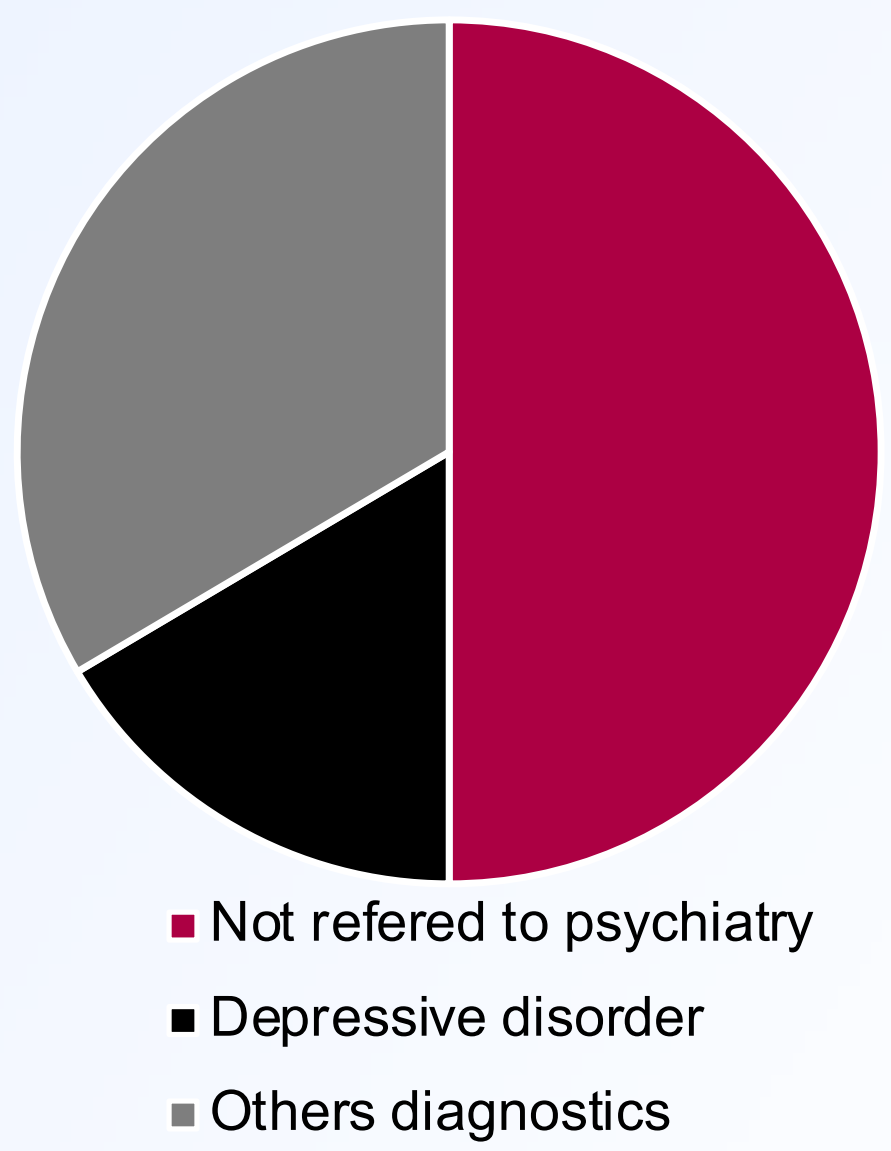

- Planned pregnancy

_Satisfactoty relationship

_Family and personal history of alcoholism

_Family and personal history of bipolar disorder

Family and personal history of depression

- Partner humiliation
Protective and risk factors

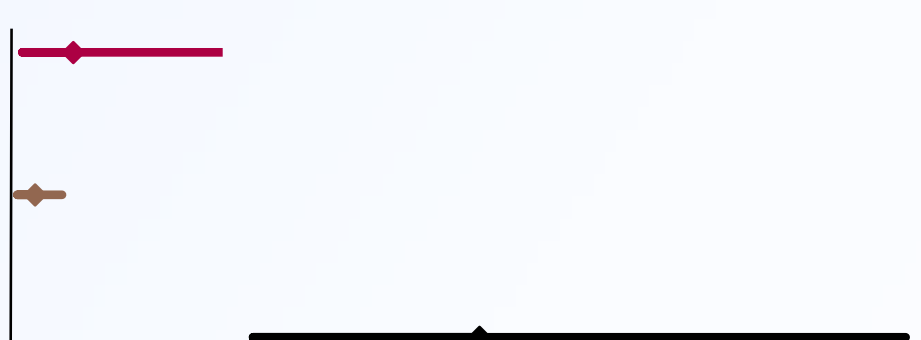

—Partner aggressiveness 